\title{
Oral Vanadyl Sulfate Improves Hepatic and Peripheral Insulin Sensitivity in Patients with Non-Insulin-dependent Diabetes Mellitus
}

\author{
Neil Cohen, Meyer Halberstam, Pavel Shlimovich, Chee Jen Chang, Harry Shamoon, and Luciano Rossetti \\ Department of Medicine and the Diabetes Research Center, Albert Einstein College of Medicine, New York 10461
}

\begin{abstract}
We examined the in vivo metabolic effects of vanadyl sulfate (VS) in non-insulin-dependent diabetes mellitus (NIDDM). Six NIDDM subjects treated with diet and/or sulfonylureas were examined at the end of three consecutive periods: placebo for $2 \mathrm{wk}$, VS (100 mg/d) for $3 \mathrm{wk}$, and placebo for 2 wk. Euglycemic hyperinsulinemic $(30 \mathrm{mU} /$ $\mathbf{m}^{2} \cdot \mathbf{m i n}$ ) clamps and oral glucose tolerance tests were performed at the end of each study period. Glycemic control at baseline was poor (fasting plasma glucose $210 \pm 19 \mathrm{mg} /$ dl; $\mathrm{HbA}_{1 \mathrm{c}} \mathbf{9 . 6 \pm 0 . 6 \% )}$ and improved after treatment (181 $\pm 14 \mathrm{mg} / \mathrm{dl}[P<0.05], 8.8 \pm 0.6 \%,[P<0.002])$; fasting and post-glucose tolerance test plasma insulin concentrations were unchanged. After VS, the glucose infusion rate during the clamp was increased (by $\sim 88 \%$, from 1.80 to $3.38 \mathrm{mg} / \mathrm{kg} \cdot \mathrm{min}, P<0.0001$ ). This improvement was due to both enhanced insulin-mediated stimulation of glucose uptake (rate of glucose disposal $\left[\mathbf{R}_{\mathrm{d}}\right],+0.89 \mathrm{mg} / \mathrm{kg} \cdot \mathrm{min}$ ) and increased inhibition of HGP $(-0.74 \mathrm{mg} / \mathrm{kg} \cdot \mathrm{min})(P$ $<0.0001$ for both). Increased insulin-stimulated glycogen synthesis $(+0.74 \mathrm{mg} / \mathrm{kg} \cdot \mathrm{min}, P<0.0003)$ accounted for $>80 \%$ of the increased $R_{d}$ after VS, and the improvement in insulin sensitivity was maintained after the second placebo period. The $K_{m}$ of skeletal muscle glycogen synthase was lowered by $\sim 30 \%$ after VS treatment $(P<0.05)$.

These results indicate that 3 wk of treatment with VS improves hepatic and peripheral insulin sensitivity in insulin-resistant NIDDM humans. These effects were sustained for up to 2 wk after discontinuation of VS. ( J. Clin. Invest. 1995. 95:2501-2509.) Key words: insulin resistance • skeletal muscle - hepatic glucose production - non-insulin-dependent diabetes mellitus • vanadium
\end{abstract}

\section{Introduction}

Non-insulin-dependent diabetes mellitus (NIDDM) ${ }^{1}$ is characterized by impaired sensitivity to insulin, particularly in skeletal

\footnotetext{
Address correspondence to Dr. Luciano Rossetti, Diabetes Research Center, Albert Einstein College of Medicine, 1300 Morris Park Avenue, Bronx, NY 10461. Phone: 718-430-4215; FAX: 718-828-6988.

Received for publication 10 November 1994 and in revised form 30 January 1995.
}

1. Abbreviations used in this paper: HGP, hepatic glucose production; NIDDM, non-insulin-dependent diabetes mellitus; OGTT, oral glucose tolerance tests.

J. Clin. Invest.

(c) The American Society for Clinical Investigation, Inc.

0021-9738/95/06/2501/09 \$2.00

Volume 95, June 1995, 2501-2509 muscle and liver $(1,2)$. Oral drug therapy aimed at controlling hyperglycemia in NIDDM often fails, and most patients require insulin treatment late in the course of their disease. This progressive deterioration in glucose metabolism is due, in part, to worsening insulin sensitivity which may be ameliorated by the glucose-lowering effect of exogenous insulin therapy (3), but a number of side effects and complications accompany insulin therapy. Therefore, agents which could augment insulin sensitivity at the level of muscle and liver may be useful in treatment of NIDDM.

The insulinomimetic properties of vanadium compounds have been well documented in vitro and in vivo (4-8). Among its several biologic effects, vanadium has been shown to stimulate glucose uptake, glycogen synthesis, and glucose oxidation in adipose cells and in skeletal muscle (4-6). As early as 1899, Lyonnet et al. (9) reported a decrease in glycosuria in two patients with diabetes given sodium vanadate. Heyliger et al. (7) first demonstrated potent in vivo effects of vanadium on carbohydrate metabolism in experimental diabetes. More recently, we have demonstrated that vanadate normalized insulinmediated glucose disposal in $90 \%$ partially pancreatectomized diabetic rats, in part due to restoration of glycogen synthetic rate in skeletal muscle (8). Vanadate treatment also increased the basal activity of the insulin receptor tyrosine kinase, an effect not observed simply with correction of hyperglycemia by phlorizin (10). Taken together with previous in vitro studies, these data suggest that vanadium ameliorates hyperglycemia via its insulinomimetic effects on hepatic and peripheral glucose metabolism.

Due to the lack of information on the effectiveness of vanadium salts in human diabetes mellitus, we undertook to study the effects of small oral doses of vanadyl sulfate in NIDDM. Vanadyl sulfate was the compound chosen because it is a form of vanadium not previously associated with overt short-term toxicity $(11-13)$. In view of data which indicate that vanadium augments insulin sensitivity in animals, we chose to study NIDDM patients in poor metabolic control who were not using insulin in a masked, placebo-controlled study design. We sought to evaluate a putative mechanism of action of the agent by examining skeletal muscle glycogen synthase activity and whole-body glucose metabolism during euglycemic hyperinsulinemic clamps. Finally, since vanadium compounds may accumulate in several tissues and exert residual biologic effects for prolonged periods in diabetic rats $(14,15)$, we studied subjects after a 2-wk baseline placebo period, after 3 wk of vanadyl sulfate treatment, and after a second 2-wk placebo period.

\section{Methods}

\section{Subjects}

Six subjects with NIDDM were recruited for study (Table I). They were generally in good health, had stable NIDDM diagnosed for at least $1 \mathrm{yr}$, and did not suffer from proliferative retinopathy, significant dia- 


\begin{tabular}{|c|c|c|c|c|c|c|}
\hline \multirow[b]{2}{*}{ Subject } & \multirow[b]{2}{*}{ Sex } & \multirow[b]{2}{*}{ Age } & \multirow[b]{2}{*}{ FFM } & \multirow[b]{2}{*}{ BMI } & \multicolumn{2}{|c|}{ Diabetes } \\
\hline & & & & & Duration & Treatment \\
\hline & & $y r$ & $k g$ & $\mathrm{~kg} / \mathrm{m}^{2}$ & & \\
\hline J. G. & $\mathbf{M}$ & 58 & 48.2 & 24.4 & $5 \mathrm{yr}$ & Glipizide $7.5 \mathrm{mg} \cdot \mathrm{qd}$ \\
\hline B. $S$. & $\mathbf{F}$ & 37 & 29.5 & 23.6 & $1 \mathrm{yr}$ & Diet \\
\hline J. U. & $\mathbf{M}$ & 61 & 47.6 & 28.0 & $4 \mathrm{yr}$ & Glyburide $5 \mathrm{mg} \cdot \mathrm{qd}$ \\
\hline R. G. & $\mathbf{M}$ & 46 & 64.4 & 38.0 & $5 \mathrm{yr}$ & Glyburide $2.5 \mathrm{mg} \cdot \mathrm{qd}$ \\
\hline H. C. & $\mathbf{F}$ & 47 & 31.9 & 24.4 & $9 \mathrm{yr}$ & Glyburide $25 \mathrm{mg} \cdot \mathrm{qd}$ \\
\hline K. R. & $\mathbf{M}$ & 48 & 43.5 & 25.1 & $7 \mathrm{yr}$ & Glyburide $5 \mathrm{mg} \cdot \mathrm{qd}$ \\
\hline Mean $( \pm S E)$ & & $50 \pm 4$ & $44.2 \pm 5.2$ & $27.3 \pm 2.2$ & $5.2 \pm 1.1$ & \\
\hline
\end{tabular}

FFM, fat free mass; BMI, body mass index.

betic renal disease, or symptomatic peripheral or autonomic neuropathy. The subjects varied in degree of obesity, with body mass index ranging from 23.6 to $38.0 \mathrm{~kg} / \mathrm{m}^{2}$ and fat-free mass (determined by ${ }^{3} \mathrm{H}_{2} \mathrm{O}$ ) from 29.5 to $64.4 \mathrm{~kg}$ (Table I). Diabetes was treated with an oral hypoglycemic agent in five subjects and with diet alone in one subject. None of the subjects was ever treated with insulin. Fitness for study was determined by history, physical examination, hematological and biochemical tests, and electrocardiography. Patients with anemia, bleeding disorders, morbid obesity, diarrhea, or recent weight changes were excluded. One subject had a remote history of a duodenal ulcer for which he took prophylactic ranitidine $(150 \mathrm{mg} / \mathrm{d})$; the same subject also had type $2 \mathrm{~b}$ hyperlipidemia which was being treated with diet. None of the subjects was engaged in an exercise program. Weight, therapeutic regimen, and metabolic control were stable in all subjects for at least 3 mo before the study. All subjects were instructed to keep their diet, physical activity, and life-style as constant as possible throughout the study period. Written informed consent was obtained in accordance with the guidelines of the Committee on Clinical Investigations of the Albert Einstein College of Medicine.

\section{Study design}

The study was a modified, single-blind placebo-controlled experiment. After an initial run-in period of $6 \mathrm{wk}$, allowing for clinical evaluation, stabilization of "study effects," and obtaining consent, the study was initiated with administration of placebo tablets (lactose $50 \mathrm{mg}$ ) twice daily for $2 \mathrm{wk}$. This initial placebo period was followed by treatment with vanadyl sulfate (in capsules identical to placebo) with two daily doses $(100 \mathrm{mg} / \mathrm{d})$ for $3 \mathrm{wk}$ (vanadyl [IV] sulfate hydrate from Spectrum Chemical Mfg. Co., Gardenia, CA was prepared by our hospital pharmacy). A second 2-wk placebo period then followed. Subject compliance was ascertained by pill count. Glycemic control was monitored by daily home capillary glucose determinations, and subjects were evaluated weekly. Within the last $3 \mathrm{~d}$ of each study period (treatment and placebo) the following were performed: $(a)$ clinical history; $(b)$ measurement of blood pressure and weight; $(c)$ oral glucose tolerance tests (OGTT); (d) full hematological and biochemical profiles including serum lipids, $\mathrm{HbA}_{\mathrm{lc}}$, serum fructosamine, and plasma vanadium concentrations; and (e) a euglycemic hyperinsulinemic clamp. After the first placebo and treatment periods, the euglycemic hyperinsulinemic clamp was performed together with skeletal muscle biopsies (see below). An identical clamp without biopsies was performed on the final day of the second placebo period.

Glucose tolerance tests. 3-h OGTTs were performed after overnight fast and abstinence from exercise, smoking, and alcohol. All subjects were instructed to withhold medications on the morning of the OGTT. The oral glucose load ( $75 \mathrm{~g}$ ) was consumed over $5 \mathrm{~min}$. Plasma glucose, insulin, C-peptide, and glucagon concentrations were determined every $30-60$ min during basal and post-glucose ingestion periods via an indwelling catheter.
Euglycemic hyperinsulinemic clamps. Subjects were instructed to take their study capsule on the morning of the clamp. They were admitted to the hospital at 0700 after an overnight fast $(9-10 \mathrm{~h})$ and infused with a continuous insulin infusion (0.5-3 U/h human insulin) through an intravenous catheter to maintain euglycemia (plasma glucose $100-$ $120 \mathrm{mg} / \mathrm{dl}$ ). To obtain arterialized venous blood samples, a contralateral hand vein was cannulated in retrograde fashion with an 18-gauge needle, and the hand was maintained at $65^{\circ} \mathrm{C}$ in a thermoregulated Plexiglas box. $2 \mathrm{~h}$ before the start of the insulin clamp, after plasma glucose concentration had declined to $130-140 \mathrm{mg} / \mathrm{dl}$, a priming dose $(21.6$ $\mu \mathrm{Ci})$ of ${ }^{3} \mathrm{H}$-3-glucose was administered and followed by a continuous infusion at $0.15 \mu \mathrm{Ci} / \mathrm{min}$. Continuous indirect calorimetry was begun $40 \mathrm{~min}$ before the start of the clamp and continued for $20 \mathrm{~min}$. A biopsy of the vastus lateralis muscle was then performed under local anesthesia ( $1 \%$ lidocaine) with a 5-mm-diameter Bergström needle. After the tracer equilibration period ( $120 \mathrm{~min}$ ), a primed, continuous infusion of insulin was initiated and maintained at a rate of $30 \mathrm{mU} / \mathrm{m}^{2} \cdot \min$ for $180 \mathrm{~min}$. Plasma glucose was maintained at euglycemia by a variable infusion of $20 \%$ glucose. Specific activity of plasma glucose was kept constant by addition of ${ }^{3} \mathrm{H}-3$-glucose tracer to the glucose infusate (16).

Blood samples for ${ }^{3} \mathrm{H}-3$-glucose and glucose concentration were taken every 15 min during the final hour of the tracer equilibration period and every 5-10 min during insulin infusion. Samples for measurement of insulin, C-peptide, FFA, and lactate concentrations were obtained every 20-30 min. 20-min periods of continuous indirect calorimetry were repeated at 60 and $150 \mathrm{~min}$ after initiation of the clamp. Protein oxidation was estimated from urinary urea nitrogen collected over the duration of the procedure (17). Immediately after the $180 \mathrm{~min}$ of hyperinsulinemia, a second muscle biopsy was performed. Muscle samples were frozen in liquid $\mathrm{N}_{2}$ within $10 \mathrm{~s}$ and stored at $-70^{\circ} \mathrm{C}$ for subsequent analysis. Upon completion of the second biopsy, euglycemia was achieved by infusing glucose, terminating the insulin infusion, and providing a meal.

Body composition. To estimate fat-free mass, body composition was measured after the first placebo period at week 2 using a bolus injection of ${ }^{3} \mathrm{H}_{2} \mathrm{O}$ (18). Fat-free body mass was estimated from total body water determinations, assayed by administration of tritiated water $(40 \mu \mathrm{Ci})$ and measurement of plasma radioactivity after equilibration.

\section{Analytic procedures}

Plasma glucose was measured with a glucose analyzer (Beckman Instruments, Inc., Fullerton, CA) with the glucose oxidase method. Plasma ${ }^{3} \mathrm{H}-$ 3-glucose radioactivity was measured in duplicate on the supernatants of barium hydroxide-zinc sulfate precipitates (Somogyi procedure) of plasma samples after evaporation to dryness to eliminate tritiated water. Plasma tritiated water specific activity was determined by liquid scintillation counting of the protein-free supernatant (Somogyi filtrate) before and after evaporation to dryness. Because tritium on the C-3 position of glucose is lost to water during glycolysis, it can be assumed that 
plasma tritium is present either in tritiated water or ${ }^{3} \mathrm{H}$-3-glucose (19, 20 ). This method to estimate whole-body glycolysis has been validated recently under hyperinsulinemic conditions (21). Plasma insulin, Cpeptide, and glucagon were determined by radioimmunoassay. Plasma FFA was measured by a colorimetric method, and plasma lactate was measured by using an enzymatic spectrophotometric assay (22). Plasma vanadate concentrations were measured by atomic absorption spectrometry (23). For indirect calorimetry, air flow, $\mathrm{O}_{2}$, and $\mathrm{CO}_{2}$ concentrations in the expired and inspired air were measured by a computerized opencircuit system (Delta Trak; Sensormedics Corp., Yorba Linda, CA). Urinary nitrogen was measured by the Kjeldahl procedure (24). $\mathrm{HbA}_{1 \mathrm{c}}$ was measured by ion exchange chromatography with an upper limit of normal of $6.2 \%$, and serum fructosamine was measured by a spectrophotometric technique. Plasma cortisol and growth hormone concentrations were measured by radioimmunoassay (25).

\section{Glycogen synthase}

Muscle glycogen synthase activity was measured by a modification ( 8 , 21 ) of the method of Thomas et al. (26) and is based on the measurement of the incorporation of radioactivity into glycogen from UDP-[U- $\left.{ }^{14} \mathrm{C}\right]-$ glucose. Tissue samples $(5-10 \mathrm{mg})$ were homogenized in $1.0 \mathrm{ml}$ of Tris/HCl buffer, $\mathrm{pH} 7.8$, containing $10 \mathrm{mM}$ EDTA, $5 \mathrm{mM}$ dithiothreitol, $50 \mathrm{mM} \mathrm{NaF}$, and $2.5 \mathrm{~g} /$ liter rabbit liver glycogen type III. The homogenate was centrifuged at $3,000 \mathrm{~g}$ for $30 \mathrm{~min}\left(\right.$ at $4^{\circ} \mathrm{C}$ ), and the supernatant was used for glycogen synthase assay by measuring the incorporation of UDP-[U- $\left.{ }^{14} \mathrm{C}\right]$-glucose into glycogen at $30^{\circ} \mathrm{C}$. Synthase activity was assayed in the presence of 0.11 and $0.22 \mathrm{mM}$ glucose-6-phosphate. Total enzyme activity was measured in the presence of $7.2 \mathrm{mM}$ glucose6-phosphate. For the kinetic analysis the assay was conducted at final concentrations of $0.003,0.017,0.033,0.090,0.330$, and $1.4 \mathrm{mM}$ UDPG; the data were linearized as Eadie-Hofstee plots and fitted using a linear regression model. The $K_{m}$ for UDPG is the reciprocal of the slope whereas $\mathrm{V}_{\max }$ is the $y$-intercept divided by the slope. Fractional velocity is calculated as the ratio of synthase activity at 0.11 and $0.22 \mathrm{mM}$ glucose-6-phosphate over total enzyme activity $(7.2 \mathrm{mM}$ glucose-6phosphate) at physiological (5-50 $\mu \mathrm{M})$ UDPG concentrations (21).

\section{Glycogen phosphorylase}

Muscle glycogen phosphorylase activity was estimated based on the measurement of the incorporation of ${ }^{14} \mathrm{C}$ into glycogen from labeled glucose-1-phosphate (27). Glycogen phosphorylase $a$, the active phosphorylated enzyme, was assayed in the absence of AMP, and phosphorylase $b$, the total enzyme activity, was assayed in the presence of 5 $\mathrm{mM}$ AMP. Tissue homogenates (5-10 mg) were prepared as described above. The supernatant was used for glycogen phosphorylase assay by measuring the incorporation of ${ }^{14} \mathrm{C}$-glucose-1-phosphate into glycogen at $30^{\circ} \mathrm{C}$ in a mixture containing $33 \mathrm{mM} \mathrm{Mes,} 200 \mathrm{mM} \mathrm{KF}, 0.45 \%$ mercaptoethanol, $15 \mathrm{mM}$ glucose-1-phosphate ( $50 \mu \mathrm{Ci} / \mathrm{mmol})$, and 3.4 $\mathrm{mg} / \mathrm{ml}$ glycogen. Phosphorylase $b$ was assayed in the same manner except that the mixture contained $100 \mathrm{mM}$ glucose-1-phosphate $(6 \mu \mathrm{Ci}$ / $\mathrm{mmol}$ ), $13.4 \mathrm{mg} / \mathrm{ml}$ glycogen, and $5 \mathrm{mM}$ AMP.

\section{Calculations}

Fasting plasma glucose during each study period was calculated by averaging fasting plasma glucose values measured on the mornings of the OGTT and the euglycemic clamp (before insulin infusion). These values were not significantly different from each other. Glucose turnover during clamp experiments was calculated using Steele's equation (28). Rates of glycolysis from plasma glucose were estimated from the increment per unit time in tritiated water $(\mathrm{dpm} / \mathrm{ml} \cdot \mathrm{min}) \times$ body water mass $(\mathrm{ml}) /{ }^{3} \mathrm{H}-3$-glucose specific activity $(\mathrm{dpm} / \mathrm{mg})$ as previously validated $(19,21)$. Glycogen synthetic rates were estimated as the difference between $\mathbf{R}_{\mathbf{d}}$ (rate of glucose disposal) and glycolysis. Carbohydrate oxidation was calculated from $\mathrm{O}_{2}$ consumption and $\mathrm{CO}_{2}$ production (corrected for protein oxidation) with the equations of Lusk (29). Data for glucose turnover, carbohydrate oxidation, and plasma hormone and substrate concentrations represent the mean values during the last 60 $\mathrm{min}$ of the basal period and the final $60 \mathrm{~min}$ of hyperinsulinemia.
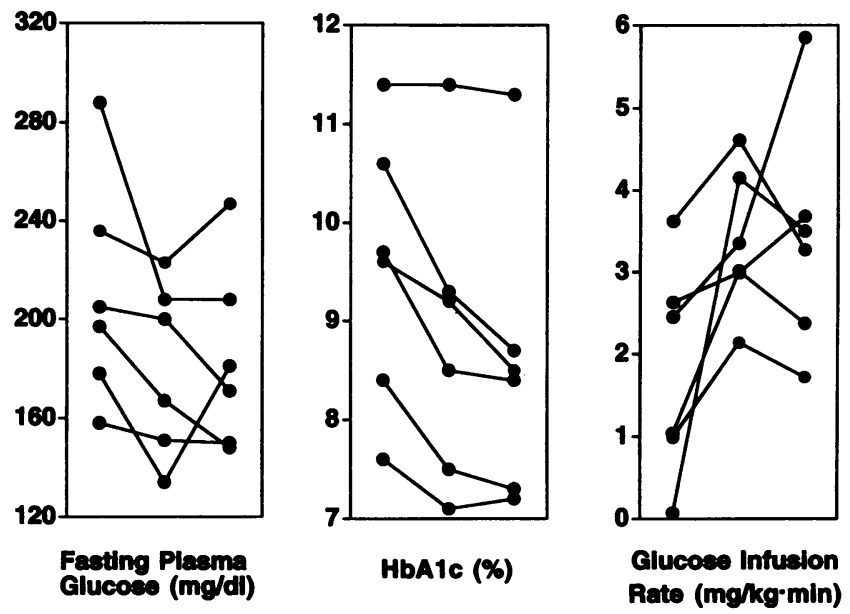

Figure 1. Values in individual subjects for fasting plasma glucose, $\mathrm{HbA}_{1 \mathrm{c}}$, and glucose infusion rate (during final $60 \mathrm{~min}$ of clamp experiments) after first placebo period, vanadyl sulfate treatment, and second placebo period. To convert $\mathrm{mg} / \mathrm{dl}$ to $\mathrm{mmol} / \mathrm{liter}$ multiply by 0.05551 . To convert $\mathrm{mg} / \mathrm{kg} \cdot \min$ to $\mu \mathrm{mol} / \mathrm{kg} \cdot \min$ multiply by 5.551 .

\section{Statistical analyses}

Repeated measurement analyses of the variables were performed using PROC MIXED (SAS/STAT User's Guide, Release 6.07, Cary, NC). The random effect considered in this mixed model is the error measurement of the individual subject, and the within-individual fixed effects are stage of study (placebo 1, vanadyl sulfate, placebo 2) and the specific time points during physiologic (clamp and OGGT) studies in each stage. For laboratory data with one observation per study period per subject, only the stage effect is considered as a fixed effect. Compound symmetry variance-covariance structure was assumed in the analysis. The likelihood ratio test was used in fitting the best model for those variables with both stage and time effects. Variables with multiple time points in each of the three study stages were hierarchically fitted using quadratic polynomials, lines of different slope, lines of equal slope, and lines of zero slope. To compare the quadratic and linear polynomial models, we calculated the difference of twice the log-likelihood function and compared the result with the critical value with 3 degrees of freedom in a $\chi$-square distribution. Using the best fitted model for each variable, comparisons among the different stages were performed by the approximate $F$ test and $t$ test.

\section{Results}

Plasma vanadium concentrations were undetectable after the first placebo period. Vanadyl sulfate administration resulted in plasma vanadium concentrations of $73.3 \pm 22.4 \mu \mathrm{g} /$ liter (not shown). 2 wk after discontinuation of the compound, plasma vanadium remained persistently detectable, though at values $\sim 13 \%$ of those observed on treatment $(9.5 \pm 2.3 \mu \mathrm{g} / \mathrm{liter})$.

At the time of evaluation for study fitness, $\mathrm{HbA}_{\mathrm{lc}}$ averaged $9.7 \pm 0.5 \%$. Fasting plasma glucose and $\mathrm{HbA}_{\mathrm{lc}}$ values after study initiation are shown in Fig. 1. Before vanadyl sulfate treatment and after 2 wk of placebo, fasting plasma glucose averaged $210 \pm 19 \mathrm{mg} / \mathrm{dl}(11.7 \pm 1.1 \mathrm{mmol} / \mathrm{liter})$ and $\mathrm{HbA}_{\mathrm{lc}}$ averaged 9.6 $\pm 0.6 \%$ ( $P=$ NS compared with baseline value $)$. After 3 wk on vanadyl sulfate, fasting plasma glucose declined significantly to $181 \pm 14 \mathrm{mg} / \mathrm{dl}(10.0 \pm 0.8 \mathrm{mmol} /$ liter, $P<0.05)$. This decrease in plasma glucose was accompanied by a parallel decline in $\mathrm{HbA}_{1 \mathrm{c}}$ to $8.8 \pm 0.6 \%(P<0.002)$. Serum fructosam- 
Table II. Clinical and Laboratory Data

\begin{tabular}{lccc}
\hline & Placebo 1 & $\begin{array}{c}\text { Vanadyl } \\
\text { sulfate }\end{array}$ & Placebo 2 \\
\hline Body weight (kg) & $79.8 \pm 10.4$ & $78.7 \pm 10.0^{*}$ & $79.0 \pm 9.4$ \\
Systolic BP (mmHg) & $129 \pm 4$ & $133 \pm 9$ & $125 \pm 3$ \\
Diastolic BP (mmHg) & $83 \pm 3$ & $84 \pm 4$ & $80 \pm 2$ \\
Serum cholesterol (mg/dl) & $198 \pm 23$ & $189 \pm 19$ & $199 \pm 25$ \\
Serum triglycerides (mg/dl) & $236 \pm 59$ & $186 \pm 56$ & $226 \pm 77$ \\
HDL cholesterol (mg/dl) & $39 \pm 3$ & $39 \pm 3$ & $40 \pm 4$ \\
LDL cholesterol (mg/dl) & $100 \pm 10$ & $105 \pm 9$ & $104 \pm 11$ \\
White blood cells/ml (10 $\left.0^{3}\right)$ & $6.5 \pm 1.0$ & $5.9 \pm 1.0$ & $6.1 \pm 0.6$ \\
Hemoglobin $(\mathrm{g} / \mathrm{dl})$ & $14.3 \pm 0.6$ & $13.3 \pm 1.0^{*}$ & $13.0 \pm 0.6^{\ddagger}$ \\
Hematocrit $(\%)$ & $41.9 \pm 1.4$ & $39.6 \pm 2.7 *$ & $39.1 \pm 2.0^{\ddagger}$ \\
Platelet count $\left(10^{3}\right)$ & $224 \pm 28$ & $214 \pm 35$ & $244 \pm 23$ \\
& & & \\
\hline
\end{tabular}

${ }^{*} P<0.05$ compared with placebo $1 ;{ }^{\ddagger} P<0.02$ compared with placebo 1 .

ine (not shown) also declined with vanadyl sulfate treatment, though not significantly, from $3.0 \pm 0.1$ to $2.8 \pm 0.2 \mathrm{mmol} / \mathrm{liter}$. Though the range of responses varied, all subjects experienced an improvement in glycemic control with vanadyl sulfate treatment. After cessation of vanadyl sulfate and resumption of placebo for $2 \mathrm{wk}, \mathrm{HbA}_{\mathrm{lc}}(8.6 \pm 0.6 \%)$ and fasting plasma glucose $(184 \pm 15 \mathrm{mg} / \mathrm{dl}[10.2 \pm 0.8 \mathrm{mmol} / \mathrm{liter}])$ remained improved compared with pretreatment values in six and four subjects, respectively. The small decline in serum fructosamine during vanadyl sulfate treatment was also maintained 2 wk after discontinuation of the vanadyl sulfate $(2.8 \pm 0.2 \mathrm{mmol} / \mathrm{liter})$.

Clinical and laboratory data during the study are shown in Table II. Transient side effects of treatment were noted in most subjects. Five patients experienced mild gastrointestinal symptoms in the first week of vanadyl sulfate treatment. These symptoms included nausea in three subjects, mild diarrhea in four subjects, and abdominal cramps in three subjects. Three subjects noted a dark discoloration of their stool during vanadium treatment, but there was no evidence of gastrointestinal bleeding. None of the subjects experienced symptoms of hyper- or hypoglycemia during the study. Body weight remained stable during the run-in period $(80.6 \pm 11.0 \mathrm{~kg})$ and was not significantly different from measurements during placebo 1 . There was a $\sim 1 \%$ decline in body weight comparing the first placebo period with the end of vanadium treatment $(P<0.05)$, but body weight was unchanged when comparing the two placebo periods. Individual changes in body weight did not correlate with changes in $\mathbf{H b A}_{\mathbf{l c}}$, fasting plasma glucose, or glucose infusion rate during clamp studies. Finally, resting energy expenditure did not change significantly in the three periods $(63.3 \pm 6.7$, $64.6 \pm 6.3$, and $65.4 \pm 6.7 \mathrm{kcal} / \mathrm{h}$ in the first placebo, vanadate, and second placebo periods, respectively). Neither appetite nor concomitant drug therapy for diabetes changed in the course of study. Throughout the duration of the study, no subject missed any dose of placebo or vanadyl sulfate because of adverse side effects. Compliance as determined by pill count was $>99 \%$.

Blood pressure, liver function tests, renal function and urinalysis, serum cholesterol, and serum triglycerides were similar in all study periods and unchanged from measurements during the run-in period before study initiation. Hematologic indices revealed a decline in hemoglobin concentration in all subjects,
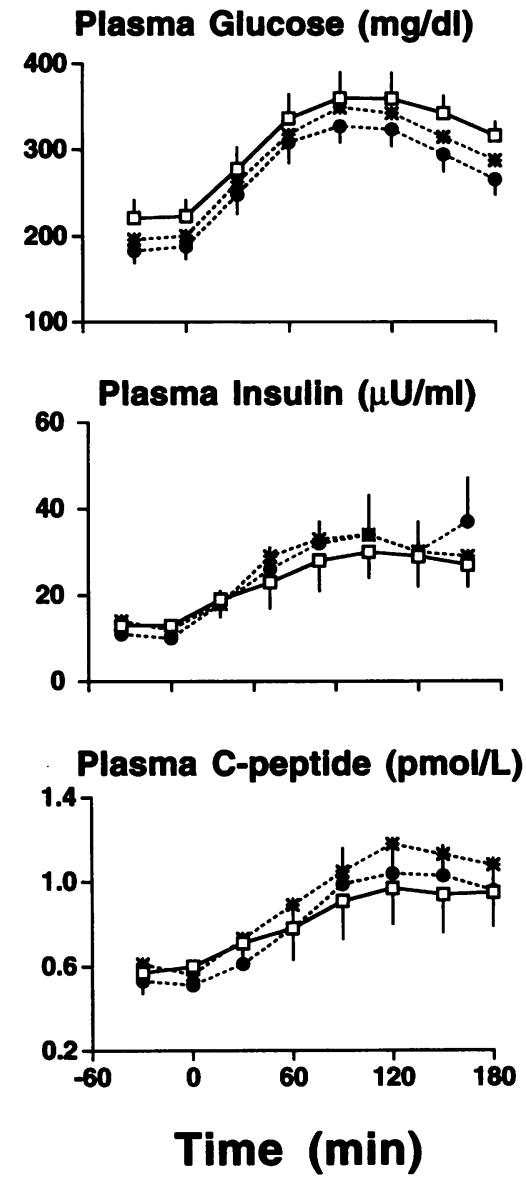

Figure 2. Plasma glucose, insulin, and C-peptide concentrations during oral glucose tolerance tests performed at the end of the first placebo period (squares), vanadyl sulfate treatment period (circles), and second placebo period (as terisks). To convert $\mathrm{mmg} / \mathrm{dl}$ to $\mathrm{mmol} / \mathrm{liter}$ multiply by 0.05551 . To convert $\mu \mathrm{U} / \mathrm{ml}$ to $\mathrm{pmol} /$ liter multiply by 6.0 .

an average of $\sim 1 \mathrm{~g} / \mathrm{dl}$ comparing the first placebo with either vanadium $(P<0.05)$ or placebo $2(P<0.02)$. This was accompanied by parallel decreases in hematocrit (Table II) but no change in red cell indices. Serum iron and iron saturation declined minimally as well (not shown). In four patients hematologic tests were repeated 3 wk after completion of the study; hemoglobin concentration remained comparable with values in the vanadyl sulfate treatment period.

The effect of vanadium treatment on dynamic glycemic responses was assessed during OGTT performed after each treatment phase (Fig. 2). While there was a decrease in fasting plasma glucose, the glycemic response during OGTT was essentially unchanged during vanadyl sulfate treatment (Fig. 2). Similarly, there were no significant changes in the insulin secretory response as reflected by either plasma insulin or plasma Cpeptide concentrations after oral glucose. Fasting plasma insulin and C-peptide levels were similar during treatment and placebo periods. Plasma glucagon concentrations were not altered by vanadyl sulfate in either fasting $(172 \pm 12$ vs $156 \pm 13 \mathrm{pg} / \mathrm{ml}$, placebo 1 and vanadyl sulfate, respectively, $P=$ NS) or postglucose challenge samples ( $158 \pm 8$ vs $153 \pm 10 \mathrm{pg} / \mathrm{ml}$, placebo 1 and vanadyl sulfate at $60 \mathrm{~min}$, respectively, $P=\mathrm{NS}$ ).

We investigated the mechanism of action of vanadyl sulfate on insulin-mediated processes during euglycemic hyperinsulinemic clamps (Fig. 3). Before the initiation of the euglycemic clamp, plasma glucose was maintained at near-euglycemic concentrations by a variable infusion of insulin. Insulin infusion rates averaged $21 \pm 3,18 \pm 2$, and $20 \pm 2 \mathrm{mU} / \mathrm{m}^{2} \cdot \min (P=\mathrm{NS})$ 

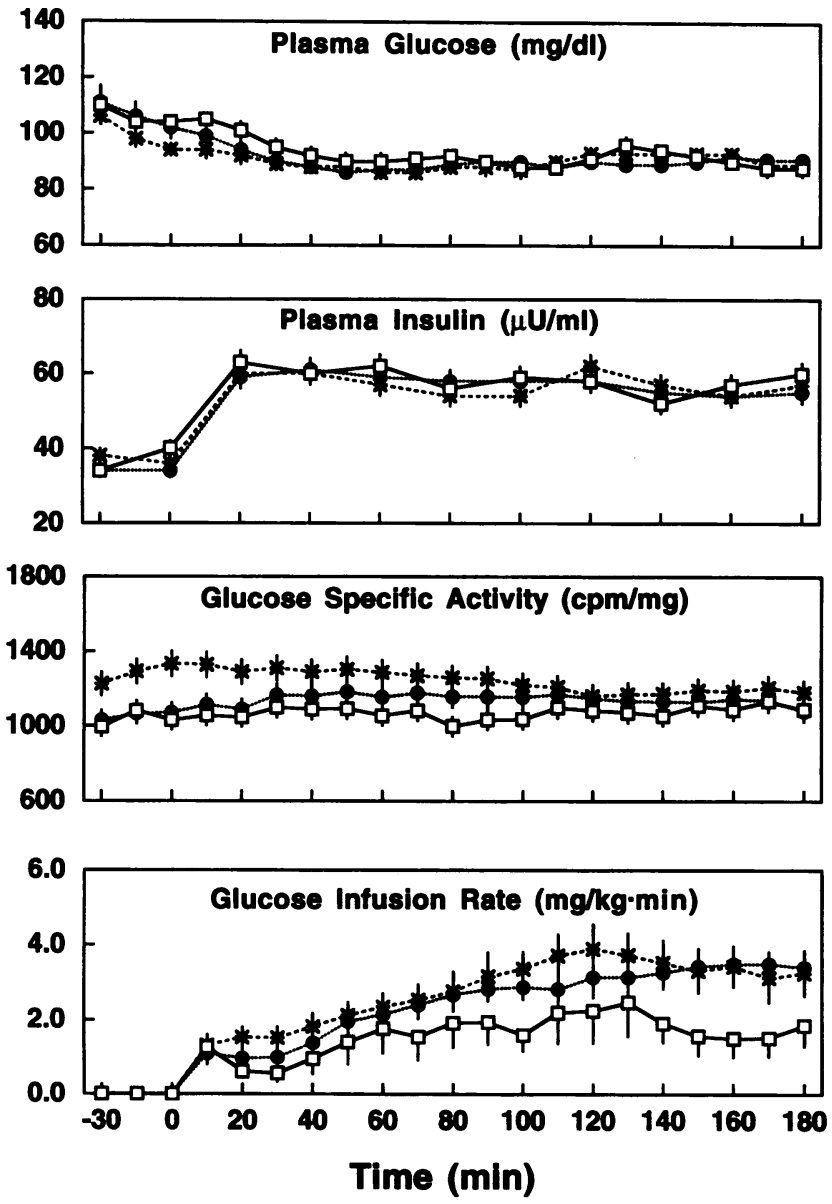

Figure 3. Plasma glucose, plasma insulin, glucose specific activity, and glucose infusion rate during clamp studies after first placebo period, vanadyl sulfate treatment, and second placebo period (see Fig. 2 legend for explanation of symbols.) To convert $\mathrm{mg} / \mathrm{dl}$ to $\mathrm{mmol} / \mathrm{liter}$ multiply by 0.05551 . To convert $\mu \mathrm{U} / \mathrm{ml}$ to pmol/liter multiply by 6.0 . To convert $\mathrm{mg} / \mathrm{kg} \cdot \min$ to $\mu \mathrm{mol} / \mathrm{kg} \cdot \min$ multiply by 5.551 .

in the three study periods. Under these basal conditions, plasma insulin concentrations averaged $34 \pm 5,36 \pm 5$, and $37 \pm 5 \mu \mathrm{U} / \mathrm{ml}$ (204 $\pm 30,216 \pm 30$, and $222 \pm 30 \mathrm{pmol} /$ liter; $P=\mathrm{NS}$ ) during first placebo, vanadium treatment, and second placebo clamps, respectively, while plasma glucose averaged $113 \pm 3,114 \pm 5$, and $108 \pm 2 \mathrm{mg} / \mathrm{dl}(6.3 \pm 0.2,6.3 \pm 0.3$, and $6.0 \pm 0.1 \mathrm{mmol} / \mathrm{liter}$; $P=$ NS), respectively. Basal hepatic glucose production (HGP) and glucose uptake were equivalent in the three studies. Subsequent to initiation of the clamp, plasma glucose concentrations were matched in the three studies $(91 \pm 1,89 \pm 1$, and $90 \pm 1 \mathrm{mg} /$ dl $[5.1 \pm 0.1,4.9 \pm 0.1$, and $5.0 \pm 0.1 \mathrm{mmol} /$ liter $])$ as were the plasma insulin concentrations $(58 \pm 3,57 \pm 3$, and $56 \pm 3 \mu \mathrm{U} /$ $\mathrm{ml}$ [348 $\pm 18,342 \pm 18$, and $336 \pm 18$ pmol/liter], Fig. 3$)$. The coefficient of variation for plasma glucose concentrations during the clamps averaged $2.5 \%$ in all three study sets. In addition, the plasma glucose specific activities for ${ }^{3} \mathrm{H}$-3-glucose were maintained at stable and comparable levels (Fig. 3 ).

The glucose infusion rate required to maintain euglycemia (Figs. 1 and 3 ) was nearly twofold greater during vanadium treatment $(3.38 \pm 0.36 \mathrm{mg} / \mathrm{kg} \cdot \min [18.76 \pm 2.00 \mu \mathrm{mol} /$ $\mathrm{kg} \cdot \mathrm{min}])$ and the second placebo $(3.40 \pm 0.58 \mathrm{mg} / \mathrm{kg} \cdot \mathrm{min}$ $[18.87 \pm 3.22 \mathrm{mmol} / \mathrm{kg} \cdot \mathrm{min}])$ compared with the first placebo
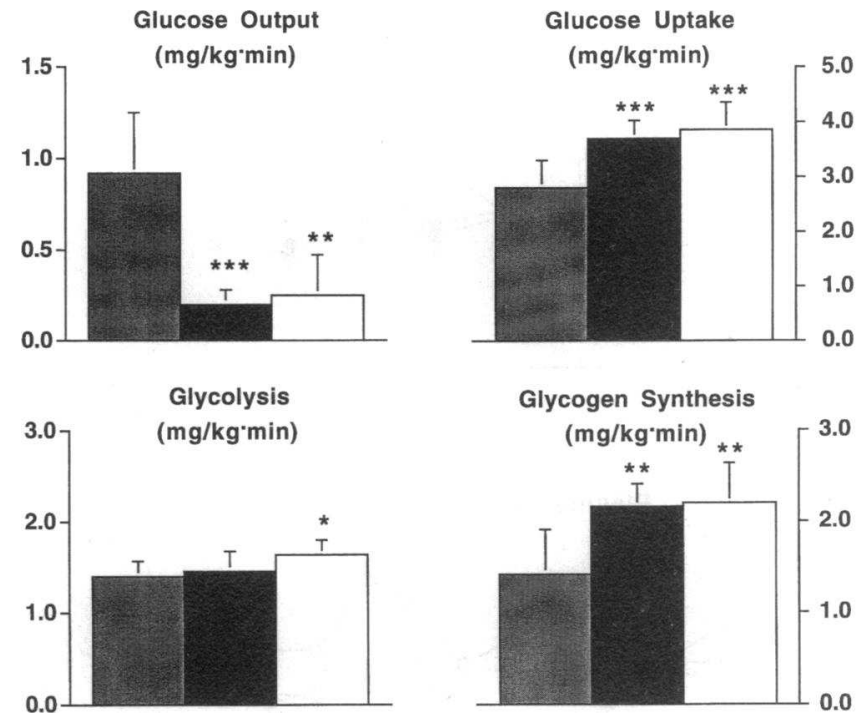

Figure 4. Rates of glucose output, glucose uptake, glycolysis, and glycogen synthesis in clamp studies after first placebo period (shaded bar), vanadyl sulfate treatment (black bar), and second placebo period (white bar). To convert $\mathrm{mg} / \mathrm{kg} \cdot \min$ to $\mu \mathrm{mol} / \mathrm{kg} \cdot \min$ multiply by 5.551 . ${ }^{*} P$ $<0.001 ; * * P<0.0003 ; * * * P<0.0001$.

period $(1.80 \pm 0.54 \mathrm{mg} / \mathrm{kg} \cdot \min [9.99 \pm 3.00 \mu \mathrm{mol} / \mathrm{kg} \cdot \min ], P$ $<0.0001)$. The increase in glucose required to maintain euglycemia during and after vanadyl sulfate treatment was apparent very early in the course of the clamps, beginning at $60 \mathrm{~min}$ and continuing throughout the study. Individual glucose infusion rates (Fig. 1) were significantly higher in clamp studies during vanadyl sulfate treatment in all six subjects and remained increased in five individuals at the end of the second placebo period (compared with first placebo period).

Before initiation of the clamps but during basal insulin infusion, HGP averaged $8.66 \pm 1.50,7.66 \pm 0.83$, and $7.72 \pm 0.56$ $\mu \mathrm{mol} / \mathrm{kg} \cdot \min$ during the three study periods $(P=\mathrm{NS})$. Glucose turnover averaged over the final $60 \mathrm{~min}$ of the clamps is shown in Fig. 4. At the end of the first placebo period, hyperinsulinemia resulted in suppression of HGP by $\sim 55 \%$. With vanadyl sulfate treatment, glucose output was nearly completely suppressed $(P<0.0001)$. This heightened sensitivity of the liver to insulin was maintained in the second placebo period ( $P<0.0003$ vs first placebo period). Similarly, insulinstimulated glucose uptake was significantly greater during vanadium treatment $(P<0.0001)$ and remained improved after reinstitution of placebo $(P<0.0001)$. The increase in glucose disposal observed during and after discontinuation of vanadyl sulfate was largely accounted for by an increase in glycogen synthesis $(P<0.0003)$, while plasma-derived glucose flux through glycolysis was minimally increased only during the second placebo period $(P<0.001)$.

Carbohydrate oxidation estimated from indirect calorimetry before initiation of the clamp was similar in all study periods, averaging $1.50 \pm 0.26,1.45 \pm 0.18$, and $1.65 \pm 0.22 \mathrm{mg} / \mathrm{kg} \cdot \mathrm{min}$ $(8.33 \pm 1.44,8.05 \pm 1.00$, and $9.16 \pm 1.22 \mu \mathrm{mol} / \mathrm{kg} \cdot \mathrm{min})$ during first placebo, vanadium treatment, and second placebo periods, respectively. After the first placebo period, in the final $30 \mathrm{~min}$ of hyperinsulinemia, carbohydrate oxidation was unchanged $(1.43 \pm 0.36 \mathrm{mg} / \mathrm{kg} \cdot \min [7.94 \pm 2.00 \mu \mathrm{mol} / \mathrm{kg} \cdot \min ])$. Hyperinsulinemia during vanadyl sulfate treatment increased carbohy- 

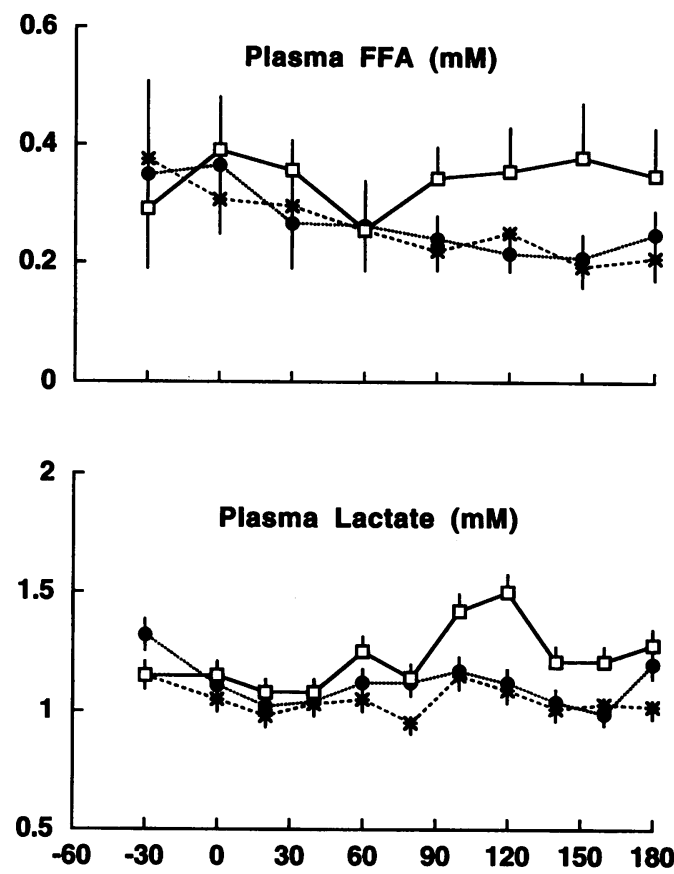

Time (min)

Figure 5. Plasma concentrations of FFA and lactate during clamp studies after first placebo period, vanadyl sulfate treatment, and second placebo period. First placebo period (squares), vanadyl sulfate treatment period (circles), and second placebo period (asterisks).

drate oxidation to $1.96 \pm 0.26 \mathrm{mg} / \mathrm{kg} \cdot \min (10.88 \pm 1.44 \mu \mathrm{mol} /$ $\mathrm{kg} \cdot \mathrm{dmin},[P<0.05])$. A modest increase in carbohydrate oxidation at the end of the clamp was also observed after the second placebo period $(1.90 \pm 0.26 \mathrm{mg} / \mathrm{kg} \cdot \min [10.55 \pm 1.44$ $\mu \mathrm{mol} / \mathrm{kg} \cdot \min ], P=\mathrm{NS})$.

Plasma FFA and lactate concentrations are depicted in Fig. 5. Basal plasma FFA concentrations were similar in all study periods. At the end of the first placebo period, hyperinsulinemia resulted in no change in plasma FFA $(0.36 \pm 0.08 \mathrm{mM})$. A significant decrease in FFA concentrations with hyperinsu- linemia was observed during vanadium administration $(0.23 \pm 0.03 \mathrm{mM}[P<0.0001])$ which persisted despite reinstitution of placebo $(0.22 \pm 0.03 \mathrm{mM}[P<0.0001])$. Basal plasma lactate concentrations were also similar in all study periods. During the last $60 \mathrm{~min}$ of hyperinsulinemia, plasma lactate was significantly lower after vanadyl sulfate treatment $(1.10 \pm 0.11$ $\mathrm{mM}[P<0.004])$ and after reinstitution of placebo $(1.04 \pm 0.14$ $\mathrm{mM}[P<0.0002])$ compared with the first placebo period (1.30 $\pm 0.10 \mathrm{mM})$. Plasma cortisol $(17 \pm 3,13 \pm 1$, and $15 \pm 1 \mu \mathrm{g} /$ $\mathrm{dl})$ and growth hormone $(0.7 \pm 0.3,2.3 \pm 0.9$, and $2.2 \pm 1.5 \mathrm{ng} /$ $\mathrm{ml})$ were similar in all three study periods ( $P=$ NS for both).

Skeletal muscle glycogen synthase and phosphorylase activities are shown in Table III. Physiologic hyperinsulinemia (clamp) did not significantly decrease the $K_{m}$ for UDPglucose or increase fractional velocity in NIDDM subjects. However, both basal and post-clamp glycogen synthase kinetics were significantly improved during vanadyl sulfate treatment compared with the first placebo period (Table III). Thus, the basal muscle glycogen synthase $K_{m}$ was decreased by $26-29 \%$ after vanadyl treatment compared with placebo $(P<0.05)$. The significant decrease in $\mathrm{K}_{\mathrm{m}}$ at the end of the insulin clamp study was completely accounted for by the improved affinity for UDPglucose under basal conditions. The $\mathrm{K}_{\mathrm{m}}$ for UDPglucose of muscle glycogen synthase was inversely correlated with the in vivo rates of glycogen synthesis $\left(r^{2}=0.58\right)$. Muscle glycogen phosphorylase activity was not affected by treatment (Table III).

\section{Discussion}

We examined the metabolic effects of vanadyl sulfate in moderately obese, conventionally controlled NIDDM subjects with significant baseline impairment of insulin sensitivity (both hepatic and peripheral). Over the course of the screening run-in period ( $6 \mathrm{wk}$ ) and baseline placebo period ( $2 \mathrm{wk})$, patients remained hyperglycemic $\left(\mathrm{HbA}_{1 \mathrm{c}} 9.7 \pm 0.5\right.$ and $9.6 \pm 0.6 \%$ at screening and at the end of the first placebo period, respectively) on unchanged treatment regimens. Vanadyl sulfate treatment for 3 wk resulted in significantly improved fasting plasma glucose and $\mathrm{HbA}_{1 \mathrm{c}}$ levels $(8.8 \pm 0.6 \%)$. This was observed despite lack of significant improvement in either serum fructosamine, plasma glucose, and insulin responses during OGTT, and in the

Table III. Basal and Post-Insulin Skeletal Muscle Glycogen Synthase and Phosphorylase Activities at the End of the First Placebo and Vanadyl Sulfate Treatment Periods

\begin{tabular}{|c|c|c|c|c|}
\hline & \multicolumn{2}{|c|}{ Placebo } & \multicolumn{2}{|c|}{ Vanadyl sulfate } \\
\hline & Basal & Insulin & Basal & Insulin \\
\hline \multicolumn{5}{|l|}{ Glycogen synthase } \\
\hline$K_{\mathrm{m} 0.11}(\mathrm{mM})$ & $0.347 \pm 0.048$ & $0.326 \pm 0.031$ & $0.248 \pm 0.036 *$ & $0.248 \pm 0.039 *$ \\
\hline $\mathrm{FV}_{0.11}(\%)$ & $23.2 \pm 2.5$ & $23.5 \pm 2.9$ & $27.7 \pm 3.6 *$ & $32.4 \pm 5.6 *$ \\
\hline$K_{\mathrm{m} 0.22}(\mathrm{mM})$ & $0.183 \pm 0.015$ & $0.170 \pm 0.020$ & $0.135 \pm 0.019^{*}$ & $0.148 \pm 0.038 *$ \\
\hline $\mathrm{FV}_{0.22}(\%)$ & $38.9 \pm 4.5$ & $43.3 \pm 2.9$ & $47.3 \pm 4.5^{*}$ & $47.8 \pm 5.9 *$ \\
\hline \multicolumn{5}{|c|}{ Glycogen phosphorylase } \\
\hline$a(\mu \mathrm{mol} / \mathrm{g} / \mathrm{min})$ & $3.8 \pm 0.5$ & $5.0 \pm 1.3$ & $5.5 \pm 0.7$ & $6.4 \pm 0.8$ \\
\hline$a / a+b(\%)$ & $11.9 \pm 3.4$ & $15.2 \pm 2.8$ & $17.6 \pm 2.7$ & $15.8 \pm 3.1$ \\
\hline
\end{tabular}

Kinetic analysis of skeletal muscle glycogen synthase and activity of skeletal muscle glycogen phosphorylase before and at 180 min during the euglycemic hyperinsulinemic clamp study. $K_{\mathrm{m}}$ and fractional velocity $(F V)$ were measured in the presence of 0.11 and $0.22 \mathrm{mM}$ glucose-6-phosphate. $* P<0.05$ versus placebo. 
absence of large changes in body weight. The clinical response to treatment was associated with marked amelioration of the resistance to insulin action, demonstrated by both improved suppression of HGP and by increased peripheral glucose uptake during the insulin clamp study. Whole body glycogen deposition was the pathway of peripheral glucose disposal which improved more dramatically. Consistent with this observation, skeletal muscle glycogen synthase activity was markedly increased. Interestingly, there were also effects on fat metabolism, with augmented suppression of lipolysis by insulin after treatment. Finally, there was evidence of prolonged effects of the treatment course lasting 2 wk after discontinuation of the compound. Vanadyl sulfate treatment was associated with mild side effects, primarily gastrointestinal, which did not require termination of treatment.

Though vanadium compounds have been given therapeutically as antiseptics, antituberculous agents, and hematinics (30), there is little systematic data in humans. Vanadium did not appear to be overtly toxic, since it was often used in relatively large doses and for prolonged periods of time $(31,32)$. The comparison with animal studies is complicated by the large differences in the administered dose and plasma vanadium levels. In fact, the minimally effective dose of vanadyl sulfate in rodents $(\sim 125 \mathrm{mg} / \mathrm{kg} / \mathrm{d})$ was $\sim 100$-fold higher than that used in the present study $(12,14,15)$, and the plasma vanadate concentration was $\sim 10$-fold lower in our patients compared with vanadium-treated diabetic rats $(7,15)$. Results of previous rat studies examining gastrointestinal and hematological effects of vanadium compounds have varied $(23,33,34)$. While a recent long-term ( 1 yr) study of nondiabetic and streptozotocindiabetic rats with vanadyl sulfate failed to demonstrate any significant changes in hematological indices at doses $\sim 100$ fold higher than used in the present study (13), increases in serum urea and creatinine concentrations and alterations in hepatic function after vanadium treatment have also been reported by some (35-37) but not others $(13,23,33,38-40)$. Increased mortality and weight loss has been reported recently in streptozotocin-diabetic rats treated with vanadate $(36)$. The use of variably insulinopenic and dehydrated animals in combination with the marked decrease in fluid intake which follows the inclusion of vanadium in drinking solution may explain some of the discrepancies on the toxic effects of the trace element in rodents $(13,23,33,35-40)$. Finally, in vitro studies have demonstrated that vanadium ions may promote genetic alterations and mitogenic effects in cultured cells $(41,42)$. Though neither the short-term toxicity nor the long-term effects of the agent have been systematically studied in humans, taken as a whole these data raise concerns about the potential use of these agents for long-term therapy of NIDDM. Since vanadium compounds are widely available without prescription, their longterm toxicity and effectiveness should be thoroughly investigated.

Among its several biologic effects, vanadium $(>200 \mu \mathrm{M})$ mimics insulin action in vitro in several isolated cell systems (4-6). In vivo studies suggesting an effect of vanadium in diabetes date as early as 1899 when Lyonnet et al. (9) reported a decrease in glycosuria in two diabetic patients given sodium vanadate. Subsequent studies in insulin-deficient streptozotocindiabetic rats $(7,39,43,44)$ and partially pancreatectomized rats $(8,45)$ as well as in obese hyperinsulinemic $f a / f a$ rats (39) have borne out this antidiabetic effect. Recent studies from our laboratory demonstrated that the normalization of plasma glucose in $90 \%$ pancreatectomized rats by vanadate treatment caused a marked improvement in skeletal muscle glycogen synthesis independent of the correction of hyperglycemia (8). Our present results confirm these observations in the rat and suggest that, in humans as well, vanadium exerts significant effects on glucose uptake and glycogen synthesis. In these insulin-resistant subjects with NIDDM, we observed significant and persistent improvement in glucose uptake and glycogen synthase activation by insulin. An enhanced suppression of lipolysis paralleled the improvement in glucose utilization.

It should be noted that our previous studies in rats did not examine the effect of vanadium on insulin-mediated inhibition of HGP since only maximal insulin response was examined (8, 45). However, Blondel et al. (44) reported improved in vivo hepatic insulin action in vanadate-treated streptozotocin-diabetic rats, and a decline in gluconeogenesis has been suggested secondary to decreased expression of the $P$-enolpyruvate carboxykinase (PEPCK) gene and increased glycolysis in the liver (46-48). A chronic hepatic effect of vanadium is consistent with the potent and significant impact of $3 \mathrm{wk}$ of treatment with vanadyl sulfate on hepatic sensitivity to insulin in our subjects with NIDDM. Indeed, HGP, though normalized by basal insulin infusion during the clamp studies, was only suppressed by $\sim 50 \%$ after the first placebo period but by $>90 \%$ after the vanadyl and second placebo periods. Though this action of vanadyl sulfate was a major component of the enhanced insulin sensitivity during physiologic euglycemic hyperinsulinemia, we cannot be certain that such enhanced effects of insulin on the liver accounted for the improvement in fasting plasma glucose and $\mathrm{HbA}_{1 \mathrm{c}}$. The time course for the response of these parameters to effective treatment in NIDDM suggests that we may have observed further improvement in metabolic control had treatment with vanadyl sulfate persisted beyond $3 \mathrm{wk}$.

The mechanism of action of vanadium on altered carbohydrate metabolism remains unclear. Recent studies in the rat provide conflicting evidence as to whether the vanadium-induced anorexia and/or weight loss accounts for its amelioration of experimental diabetes (49). Importantly, the potent effects of vanadate treatment on plasma glucose concentration and insulin action were also observed in pair-fed $90 \%$ pancreatectomized (8) and obese hyperinsulinemic $f a / f a$ rats (39). In our subjects, anorexia was not observed, and resting energy expenditure was not augmented by vanadate. Furthermore, we are not aware of published data that indicate that the minimal decline in body weight we observed during treatment can explain the marked changes in glucose metabolism. Other postulated effects include a reduction in $\mathrm{Na}^{+}$-dependent glucose transport in small intestine (50). Previous studies from our laboratory indicated that vanadate treatment in diabetic rats improved the basal insulin receptor tyrosine kinase activity with no change in insulin-stimulated activity (10). Other in vitro studies have suggested that vanadate may exert effects through activation of mitogen-activating protein kinase activity independent of insulin receptor autophosphorylation (51). The increased basal activation of skeletal muscle glycogen synthase observed in this study is consistent with a preliminary report on the activation of basal mitogen-activating protein kinase activity in circulating monocytes in NIDDM patients treated with vanadate for 2 wk (52). However, in this study, 2 wk of treatment with $\mathrm{Na}$-metavanadate did not show significant changes in fasting plasma glucose, $\mathrm{HbA}_{\mathrm{lc}}$, or serum fructosamine in four NIDDM subjects.

Whether the in vivo actions of vanadyl sulfate in NIDDM 
can be attributed to these or other mechanisms cannot be determined from this study. As with previous studies $(7,8,38,43)$, we can be confident that the improvement in glucose metabolism was not due to an increase in plasma insulin concentrations since neither fasting nor post-OGTT plasma insulin or C-peptide concentrations were higher after 3 wk of vanadyl sulfate. However, since plasma insulin concentrations were not reduced in the setting of decreased hyperglycemia, it may be argued that there may have been some amelioration of glucose-induced insulin secretion, perhaps indirectly via reduction of glucose toxicity $(53,54)$. In addition, there was no evidence that insulin counterregulatory hormones were decreased by treatment.

Finally, we found a remarkable persistence of the effects of vanadyl sulfate after discontinuation of the agent for 2 wk. These findings are consistent with studies that have documented the beneficial effects of vanadyl treatment for up to $13 \mathrm{wk}$ after withdrawal of treatment in diabetic rats (14). Though plasma vanadium concentrations remained detectable 2 wk after withdrawal, it is unlikely that the persistent effects were due solely to these residual circulating levels of the trace element. In vivo administration of vanadate or vanadyl sulfate to diabetic animals appears to require a lag time to manifest its effects on carbohydrate metabolism, and the tissue distribution of the element is widespread (23). Indeed, though vanadate transport into intact cells is a relatively slow process, several in vitro effects on glucose metabolism have been observed within minutes (4-6). We observed virtually identical changes in glucose homeostasis in the clamps after the second placebo period as after vanadyl sulfate treatment, though we did not obtain skeletal muscle biopsies at this point of the study. Whether some of the longterm effects we observed are due to persistence of vanadium action per se or to the 3-wk improvement in carbohydrate and fat metabolism remains to be elucidated.

In summary, this study provides evidence for potent metabolic effects of vanadium in humans with NIDDM. 3 wk of treatment with a low, well-tolerated dose of vanadyl sulfate resulted in decreased fasting plasma glucose and $\mathrm{HbA}_{1 \mathrm{c}}$ concentrations in the absence of increased plasma insulin concentration. During euglycemic clamp studies, the hepatic and peripheral responses to physiologic hyperinsulinemia were markedly improved. Importantly, these beneficial metabolic effects of vanadyl sulfate were sustained for at least 2 wk after discontinuation of treatment. These results underscore the need for further investigation to establish the safety and long-term effectiveness of vanadium compounds in human diabetes.

\section{Acknowledgments}

We are grateful to Anne Thomashunis and Helena Duffy for the care of the subjects, to Robin Sgueglia, Wei Chen, and Ken Richman for technical assistance, and to the Radioimmunoassay Core Laboratory of the Diabetes Research and Training Center for plasma insulin and glucagon determinations.

This work was supported by National Institutes of Health grant RO1DK47477 and a National Institutes of Health Fellowship Training Grant.

\section{References}

1. Butler, P. C., E. J. Kryshak, W. F. Schwenk, M. W. Haymond, and R. A. Rizza. 1990. Hepatic and extrahepatic responses to insulin in NIDDM and nondiabetic humans. Assessment in absence of artifact introduced by tritiated nonglucose contaminants. Diabetes. 39:217-225.

2. DeFronzo, R. A., D. Simonson, and E. Ferrannini. 1982. Hepatic and peripheral insulin resistance: a common feature of type 2 (non-insulin-dependent) diabetes mellitus. Diabetologia. 23:313-319.

3. Yki-Järvinen, H. 1992. Glucose toxicity. Endocr. Rev. 13:415-431.

4. Dubyak, G. R., and G. Kleinzeller. 1980. The insulin-mimetic effects of vanadate in isolated rat adipocytes. J. Biol. Chem. 255:5306-5312.

5. Shechter, Y. 1990. Insulin-mimetic effects of vanadate: possible implications for future treatment of diabetes. Diabetes. 39:1-5.

6. Clausen, T., T. L. Andersen, M. Sturup-Johansen, and O. Petkova. 1981. The relationship between the transport of glucose and cations across cell membranes in isolated tissues. The effect of vanadate in ${ }^{45} \mathrm{Ca}$-efflux and sugar transport in adipose tissue and in skeletal muscle. Biochim. Biophys. Acta. 646:261-267.

7. Heyliger, C. E., A. G. Tahiliani, and J. H. McNeill. 1985. Effect of vanadate on elevated blood glucose and depressed cardiac performance of diabetic rats. Science (Wash. DC). 227:1474-1477.

8. Rossetti, L., and M. R. Laughlin. 1989. Correction of chronic hyperglycemia with vanadate, but not with phlorizin, normalizes in vitro glycogen synthase activity in diabetic skeletal muscle. J. Clin. Invest. 84:892-899.

9. Lyonnet, B., Martz, and E. Martin. 1899. L'emploi therapeutique des derives du vanadium. La Presse Medicale. 1:191-192.

10. Cordera, R., G. Andraghetti, R. A. DeFronzo, and L. Rossetti. 1990. Effect of in vivo vanadate treatment on insulin receptor tyrosine kinase activity in partially pancreatectomized diabetic rats. Endocrinology. 126:2177-2183.

11. Hudson, T. G. F. 1964. Vanadium, toxicology and biological significance. In Elsevier Monographs on Toxic Agents. E. Browing, editor. Elsevier Science Publishing Co., Inc., New York.

12. Ramanadham, S., J. J. Mongold, R. W. Brownsey, G. H. Cros, and J. H. McNeill. 1989. Oral vanadyl sulfate in treatment of diabetes mellitus in rats. Am. J. Physiol. 257:H904-H911.

13. Dai, S., and J. H. McNeill. 1994. One-year treatment of non-diabetic and streptozotocin-diabetic rats with vanadyl sulphate did not alter blood pressure or haematological indices. Pharmacol. \& Toxicol. 74:110-115.

14. Pederson, R. A., S. Ramanadham, A. M. J. Buchan, and J. H. McNeill. 1985. Long-term effects of vanadyl treatment on streptozotocin-induced diabetes in rats. Diabetes. 38:1390-1395.

15. Cam, M. C., R. A. Pederson, R. W. Brownsey, and J. H. McNeill. 1993. Long-term effectiveness of oral vanadyl sulphate in streptozotocin-diabetic rats. Diabetologia. 36:218-224.

16. Finegood, D. T., R. N. Bergman, and M. Vranic. 1987. Estimation of endogenous glucose production during hyperinsulinemic-euglycemic glucose clamp: comparison of unlabeled and labeled glucose infusates. Diabetes. 36:914924.

17. Ferrannini, E. 1988. The theoretical basis of indirect calorimetry: a review. Metab. Clin. Exp. 37:287-301.

18. Wolfe, R. R. 1984. Total body water. In Tracers in Metabolic Research. Alan R. Liss, Inc., New York. 175-178.

19. Rossetti, L., and A. Giaccari. 1990. Relative contribution of glycogen synthesis and glycolysis to insulin-mediated glucose uptake. A dose-response euglycemic clamp study in normal and diabetic rats. J. Clin. Invest. 85:17851792.

20. Young, A. A., C. Bogardus, D. Wolfe-Lopez, and D. M. Mott. 1988. Muscle glycogen synthesis disposition of infused glucose in humans with reduced rates of insulin-mediated carbohydrate storage. Diabetes. 37:303-308.

21. Rossetti, L., Y.-T. Lee, J. Ruiz, S. Aldridge, H. Shamoon, and G. Boden. 1993. Quantitation of glycolysis and skeletal muscle glycogen synthesis in humans. Am. J. Physiol. 265:E761-E769.

22. Gawehn, K. 1986. D-lactate. In Methods of Enzymatic Analysis. H. Bergmeyer and M. Gassl, editors. VCH Publishers, Inc., New York. VI:583-592.

23. Mongold, J. J., G. H. Cros, L. Vian, A. Tep, S. Ramanadham, G. Siou, J. Diaz, J. H. McNeill, and J. J. Serrano. 1990. Toxicological aspects of vanadyl sulphate on diabetic rats: effects on vanadium levels and pancreatic B-cell morphology. Pharmacol. \& Toxicol. 67:192-198.

24. Hawk, P. 1947. The Kjeldahl method. In Practical Physiological Chemistry, 12th ed. Blakiston and Co., Toronto. 814-822.

25. Sotsky, M. J., S. Shilo, and H. Shamoon. 1989. Regulation of counterregulatory hormone secretion in man during exercise and hypoglycemia. J. Clin. Endocrinol. Metab. 68:9-17.

26. Thomas, J. A., K. K. Schlender, and J. Larner. 1968. A rapid filter paper assay for UDP-glucose-glycogen glucosyltransferase, including an improved biosynthesis for UDP $\left({ }^{14} \mathrm{C}\right)$ glucose. Anal. Biochem. 25:486-499.

27. Rossetti, L., S. Farrace, S. B. Choi, A. Giaccari, L. Sloan, S. Frontoni, and M. S. Katz. 1993. Multiple metabolic effects of calcitonin gene-related peptide (CGRP) in conscious rats. Relationship to its regulation of glycogen synthase and adenylate cyclase. Am. J. Physiol. 264:E1-E10.

28. Steele, R. 1959. Influences of glucose loading and of injected insulin on hepatic glucose output. Ann. NY Acad. Sci. 82:420-430.

29. Lusk, G. 1924. Animal calorimetry: analysis of the oxidation of mixtures of carbohydrate and fat. J. Biol. Chem. 59:41-42.

30. Busch, P. M. 1961. Vanadium. A materials survey. Bureau of Mines. I.C. 8060. U.S. Dept. of Interior. 
31. Curran, G. L. 1954. Effect of certain transition group elements on hepatic synthesis of cholesterol in the rat. J. Biol. Chem. 210:765-770.

32. Dimond, E. G., J. Caravaca, and A. Benchimol. 1963. Vanadium. Excretion, toxicity, lipid effect in man. Am. J. Clin. Nutr. 12:49-53.

33. Dai, S., V. G. Yuen, C. Orvig, and J. H. McNeill. 1993. Prevention of diabetes-induced pathology in STZ-diabetic rats by bis(maltolato)oxovanadium (IV). Pharmacology Communications. 3:311-321.

34. Zaporowska, H., and W. Wasilewski. 1989. Some selected peripheral blood and haemopoietic system indices in Wistar rats with chronic vanadium intoxication. Comp. Biochem. Physiol. 93C:175-180.

35. Kubena, L. F., R. B. Harvey, O. J. Fletcher, T. D. Phillips, H. H. Mollenhauer, D. A. Witzel, and N. D. Heidelbaugh. 1983. Toxicity of ochratoxin A and vanadium to growing chicks. Poult. Sci. 64:620-628.

36. Domingo, J. L., M. Gomez, J. M. Llobet, J. Corbella, and C. L. Keen. 1991. Oral vanadium administration to streptozotocin-diabetic rats has marked negative side-effects which are independent of the form of vanadium used. Toxicology. 66:279-287.

37. Younes, M., and O. Strubelt. 1991. Vanadate-induced toxicity towards isolated perfused rat livers: the role lipid peroxidation. Toxicology. 66:63-74.

38. Brichard, S. M., W. Okitolonda, and J. C. Henquin. 1988. Long term improvement of glucose homeostasis by vanadate treatment in diabetic rats. Endocrinology. 123:2048-2053.

39. Brichard, S. M., A. M. Pottier, and J. C. Henquin. 1989. Long term improvement of glucose homeostasis by vanadate in obese hyperinsulinemic fa/ fa rats. Endocrinology. 125:2510-2516.

40. Al-Bayati, M. A., S. N. Giri, and O. G. Raabe. 1990. Time and doseresponse study of the effects of vanadate in rats: changes in blood cells, serum enzymes, protein, cholesterol, glucose, calcium, and inorganic phosphate. J. Environ. Pathol. Toxicol. Oncol. 10:206-213.

41. Owuso-Yaw, J., S. Y. Cohen, and C. I. Wei. 1990. An assessment of the genotoxicity of vanadium. Toxicol. Lett. (Amst.). 50:327-336.

42. Sabbioni, E., G. Pozzi, A. Pintar, L. Casella, and S. Garattini. 1991. Cellular retention, cytotoxicity and morphological transformation by vanadium (IV) and vanadium (V) in BALB/3T3 cell lines. Carcinogenesis (Oxf.). 12:4752.

43. Meyerovitch, J., Z. Farfel, J. Sack, and Y. Shechter. 1987. Oral administra- tion of vanadate normalizes blood glucose levels in streptozotocin-treated rats: characterization and mode of action. J. Biol. Chem. 262:6658-6662.

44. Blondel, O., D. Bailbe, and B. Portha. 1989. In vivo insulin resistance in streptozotocin-diabetic rats-evidence for reversal following oral vanadate treatment. Diabetologia. 32:185-190.

45. Rossetti L., A. Giaccari, E. Klein-Robbenhaar, and L. R. Vogel. 1990. Insulinomimetic properties of trace elements and characterization of in vivo mode of action in diabetic rats. Diabetes. 39:1243-1250.

46. Valera, A., J. E. Rodriguez-Gil, and F. Bosch. 1993. Vanadate treatment restores the expression of genes for key enzymes in the glucose and ketone bodies metabolism in the liver of diabetic rats. J. Clin. Invest. 92:4-11.

47. Miralpeix, M., J.-F. Decaux, A. Kahn, and R. Bartrons. 1991. Vanadate induction of L-type pyruvate kinase mRNA in adult rat hepatocytes in primary culture. Diabetes 40:462-464.

48. Brichard, S. M., B. Desbuquois, and J. Girard. 1993. Vanadate treatment of diabetic rats reverses the impaired expression of genes involved in hepatic glucose metabolism: effects on glycolytic and gluconeogenic enzymes, and on glucose transporter GLUT2. Mol. Cell. Endocrinol. 91:91-97.

49. Malabu, U. H., S. Dryden, H. D. McCarthy, A. Kilpatrick, and G. Williams. 1994. Effects of chronic vanadate administration in the STZ-induced diabetic rat: the antihyperglycemic action of vanadate is attributable entirely to its suppression of feeding. Diabetes. 43:9-15.

50. Madsen, K. L., V. M. Porter, and R. N. Fedorak. 1993. Oral vanadate reduces $\mathrm{Na}+$-dependent glucose transport in rat small intestine. Diabetes. 42:1126-1132.

51. D'Onofrio, F., M. Q. Le, J. L. Chiasson, and A. K. Srivastava. 1994 Activation of mitogen-activating protein (MAP) kinases by vanadate is independent of insulin receptor autophosphorylation. FEBS (Fed. Eur. Biochem. Soc.) Lett. 340:269-275.

52. Goldfine, A. B., F. Folli, M. E. Patti, D. C. Simonson, and C. R. Kahn. 1994. Effects of sodium vanadate on in vivo and in vitro insulin action in diabetes. Clin. Res. 42:116A.

53. Bonner-Weir, S., D. F. Trent, and G. C. Weir. 1983. Partial pancreatectomy in the rat and subsequent defect in glucose-induced insulin release. J. Clin. Invest. 71:1544-1553.

54. Rossetti, L., G. I. Shulman, W. Zawalich, and R. A. DeFronzo. 1987. Effect of chronic hyperglycemia on in vivo insulin secretion in partially pancreatectomized rats. J. Clin. Invest. 80:1037-1044. 